\title{
Rancangan Sistem Otomatis Buka Tutup Bak Sampah Berbasis Mikrokontroler AT89S52 Dan Sensor Metal Detektor
}

\section{Sistem Desind Automatic Open And Close Waste Based AT89S52 Microcontroller And Sensor Metal Detector}

\author{
Muhammad Ardiansyah Purba,1) Dadan Ramdan2), Faisal Irsan Pasaribu ${ }^{3)}$ \\ Program Studi Teknik Elektro, Fakultas Teknik \\ Universitas Medan Area, Indonesia
}

*Coresponding author: ardiansyah8888@gmail.com

\begin{abstract}
Abstrak
Proyek akhir buka tutup bak sampah menggunakan mikrokontroler AT89S52 ini dirancang untuk memudahkan pengguna dalam membuang sampah pada tempatnya tanpa harus menentukan jenis sampah dengan manual. Dalam hal ini sampah dipilih berdasarkan sampah logan dan non logam. Metode yang digunakan untuk mendeteksi keberadaan obyek ini adalah metode rancang bangun yang menggunakan sensor metal dan motor penggerak jenis DC ini terbagi menjadi dua bagian, yaitu bagian hardware dan software. Hardware terdiri dari sensor metal, sensor infra merah, sistem minimum mikrokontroler AT89S52 sebagai rangkaian pengendali input dan output, 4N25 sebagai IC driver motor dc. Sedangkan software yang dibuat menggunakan program 8051. Unjuk kerja tempat sampah otomatis menggunakan mikrokontroler AT89S52 ini secara keseluruhan dapat bekerja dengan baik, sehingga efektif memilih jenis sampah.
\end{abstract}

Kata Kunci : Sampah, Sensor Metal, mikrokontroler AT89S52

\begin{abstract}
Final project of automatic trash bin using AT89S52 microcontroller was designed to facilitate the user to throw the trash in place without should to determine type the trash of manually.In this case the waste was selected on the basis of metal and non-metalilic waste.The method was used to detect the existence of this object is a design method that uses metal sensors and DC type that contains in two parts,such as hardware and software parts.The hardware consists of a metal sensor,infrared sensor,minimum system of AT89S52 microcontroller as input and output controller, $4 N$ as IC driver of motor DC.the software was created using program 8051 for automatic trash bin using this AT89S52 microcontroller as a whole can work was better and more effectively to choose the kinds of trash.
\end{abstract}

Keywords : Trash, Metal Sensor, microcontroller AT89S52,

How to Cite: Purba, M. A , Dadan , R, dan Pasaribu, F.I .(2016), Rancangan sistem otomatis buka tutup bak sampah berbasis mikrokontroler AT89S52 dan sensor metal detektor, 2(1): 13-20 


\section{PENDAHULUAN}

Pada saat sekarang ini telah banyak kita dengar melalui media elektronik maupun media cetak berbagai macam peristiwa kebanjiran mulai dari banjir bandang di daerah Aceh, Jawa, bahkan meluapnya air sungai hingga masuk ke daerah pemukiman warga dan akhirnya banyak menelan korban seperti akhirakhir ini yang melanda daerah Binjai Medan Sumatera Utara. Peristiwa ini dapat terjadi karena salah satu faktor penyebabnya yaitu kurangnya kesadaran manusia dalam menjaga kebersihan lingkungan.

Lingkungan yang tidak bersih pada saat ini memang sudah tidak pembicaraan yang asing lagi ditelinga kita, apalagi daerah-daerah yang padat penduduknya tentunya pemandangan yang dapat kita saksikan adalah banyaknya serakan sampah dimana-mana baik di jalanan, selokan, sungai-sungai, bahkan tempat yang sudah disediakan tempat pembuangan sampahpun masih banyak sampah yang berserakan.

Jika hal ini dipertanyakan kepada sekelompok orang mengapa serakan sampah masih juga sering terlihat di depan mata padahal tempat pembuangan sampah sudah disediakan, salah satu jawaban konyol dari mereka adalah malas. Alasan mengapa malas membuang sampah pada tempatnya adalah karena terkadang tempat pembuangan sampah tersebut kotor sehingga orang yang akan membuang sampah merasa takut apalagi kalau bak sampahnya pakai tutup sehingga harus membuka tutup bak sampah terlebih dahulu karena tutupnya bau dan kotor.

Dari alasan tersebut di atas muncul ide peneliti untuk membuat rancangan bak sampah yang dapat bekerja secara otomatis membuka dan menutup bak sampah, dengan harapan agar manusia yang ingin membuang sampah merasa tidak jijik lagi apabila ingin buang sampah. Dan bahkan jika hal ini terwujud maka pemandangan sampah yang dahulunya terlihat berserakan dimana-mana paling tidak menjadi semakin berkurang.

Adapun yang menjadi rumusan masalah dalam penelitian ini adalah :

1. Apa saja objek yang dapat dideteksi oleh sistem agar dapat bekerja membuka dan menutup bak sampah

2. Bagaimanakah sistem elektronik yang digunakan pada alat sehingga dapat bekerja optimal.

Yang menjadi batasan masalah dalam penelitian ini adalah :

1. Penelitian yang disajikan ini adalah berbentuk studi rancang bangun alat yang seluruh komponen pembentuknya dijelaskan secara mendetail dan ilmiah dalam laporan ini.

2. Ruang lingkup pembahasan meliputi perangkat hardware dan software

3. Jenis sampah yang dapat dibuang pada bak sampah adalah jenis metal dan non metal dengan dua arah pembuangan tutup bak sampah.

Maksud dari perancangan ini adalah :

1. Merancang sistem otomatis buka tutup bak sampah dengan dua arah pembuangan yaitu untuk jenis sampah metal dan bukan metal.

2. Merancang sistem hardware maupun software pengendali arah putar bak sampah sehingga mampu dengan cerdas menyeleksi dan membuang jenis sampah ke arah pembuangan yang tepat. 
3. Membuat sistem elektronik bak sampah dari komponen yang tepat guna serta memiliki sistem kerja yang saling mendukung satu sama lain pada masing-masing rangkaian.

Tujuan dari perancangan alat adalah sebagai berikut:

1. Dapat memudahkan pengguna dalam memasukkan sampah ke tempatnya.

2. Menghindari manusia dari kotoran ataupun kuman ketika hendak membuang sampah pada bak.

3. Mengurangi dampak lingkungan kotor seperti penyakit dan kebanjiran.

4. Membantu petugas kebersihan dalam menyeleksi sampah organik dan non organik sehingga mempermudah dalam pengolahannya.

5. Membuat masyarakat sadar akan pentingnya kesehatan dengan membuang sampah pada tempatnya.

\section{METODE PENELITIAN}

Kegiatan penelitian dilakukan di Laboratorium Dasar Digital Jurusan Teknik Elektro Fakultas Teknik Universitas Medan Area Jl. Kolam No. 1 Medan Estate, Sumatera Utara.

Sistem otomatis buka tutup bak sampah yang akan dirancang secara garis besar ditunjukkan pada blok diagram Gambar 1 berikut.

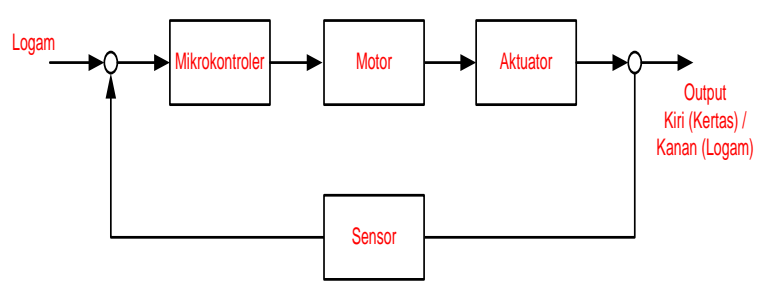

Gambar 1 : Blok diagram System (Hasil Penelitian)
Dari Gambar 1 di atas dapat dilihat bahwa untuk bagian sumber tenaga pada penelitian ini digunakan power supply yang berfungsi sebagai pensupply tenaga listrik keseluruh sistem pembentuk alat buka tutup otomatis bak sampah. Selanjutnya untuk bagian input digunakan sensor photodioda, sensor optocoupler, dan metal detector, kemudian pada bagian sistem pengendali yang digunakan adalah mikrokontroler AT89S52 yang berfungsi sebagai penerima, pemroses data dan mengeluarkan data tersebut dalam bentuk sinyal digital ataupun analog untuk disampaikan kepada bagian output yaitu motor dc servo.

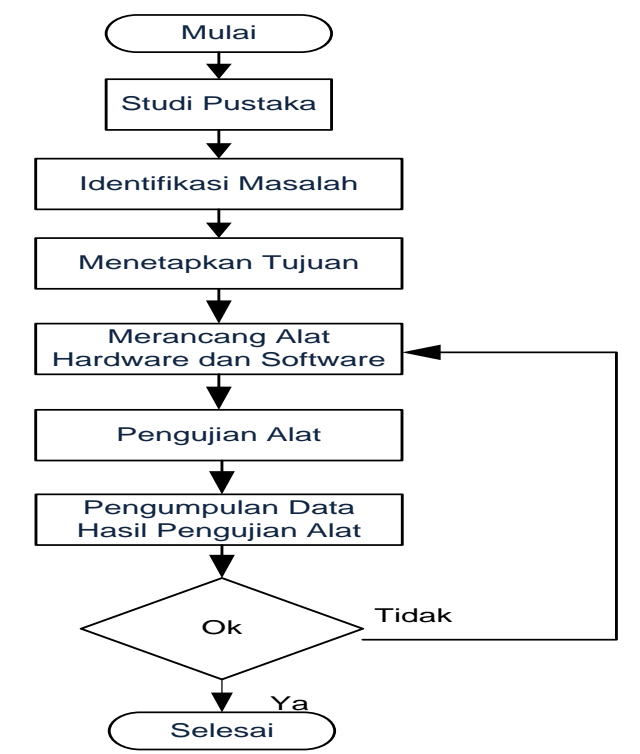

Gambar 2 : Flowchart kerangka berfikir (Hasil Penelitian)

Dalam perencanaan dan pembuatan sistem otomatis buka tutup bak sampah yang dikendalikan oleh mikrokontroler AT89S52 ini dalam pengerjaannya melalui tiga tahap, perancangan perangkat keras, perangkat mekanik, dan perancangan perangkat lunak.

Perancangan perangkat mekanik meliputi perancangan sistem buka tutup 
bak sampah dengan dua arah yang berbentuk trapesium sama kaki, dan untuk bentuk sistem penampung sampah bagian dalam adalah mengikuti bentuk bak sampah bagian luar. Dalam proses awal pembuatan ditentukan terlebih dahulu bahan yang digunakan, dan letak perangkat kerasnya.

Pada perancangan perangkat keras meliputi perancangan rangkaian sistem minimum mikrokontroler, rangkaian driver relay, rangkaian sensor infra red photodioda, dan rangkaian sensor metal. Sedangkan pada perancangan perangkat lunak meliputi program yang dibuat dengan bahasa assembly yang nantinya akan didownload ke mikrokontroler AT89S52. adalah :

Adapun bahan yang digunakan

1. Mikrokontroler AVR ATMega16

2. LED Infra Merah

3. Sensor Fhotodioda

4. Sensor Metal

5. Sensor Optocoupler

6. Relay

7. Trafo

8. Resistor

9. Kapasitor

10. Dioda

11. Transistor

12. Led

13. IC 7805

Adapun alat yang digunakan dalam pembuatan sistem otomatis buka tutup bak sampah adalah :

1. Solder listrik

2. Penyedot timah

3. Bor $P C B$ dan mata bor $1 \mathrm{~mm}$

4. Alat potong berupa gergaji dan cutter

5. Project Board

6. Tang jepit dan tang potong
7. Alat ukur berupa multitester

8. Ferry Chloride $\left(\mathrm{FeCl}_{3}\right)$

9. $P C B$ polos

10. Amplas halus

Bahan yang digunakan dalam pembuatan perangkata lunak sebagai program untuk didownload ke mikrokontroler AT89S52 adalah Software 8051 dengan bahasa Assembly. (Budiharto, Widodo)

Adapun alat yang digunakan agar dapat membuat ataupun menulis program yang nantinya akan dimasukkan ke dalam mikrokontroler adalah : (Tague, N. R)

1. Komputer

2. Rangkaian downloader

3. Kabel data (AT ProgISP)

Adapun bahan yang digunakan dalam pembuatan sistem mekanik buka tutup bak sampah adalah tutup bawaan dari bak sampah yang dibeli dari toko, lalu dimodifikasi sesuai kebutuhan desain alat. Berikut Gambar 3 yang memperlihatkan tutup bak sampah yang dimodifikasi :

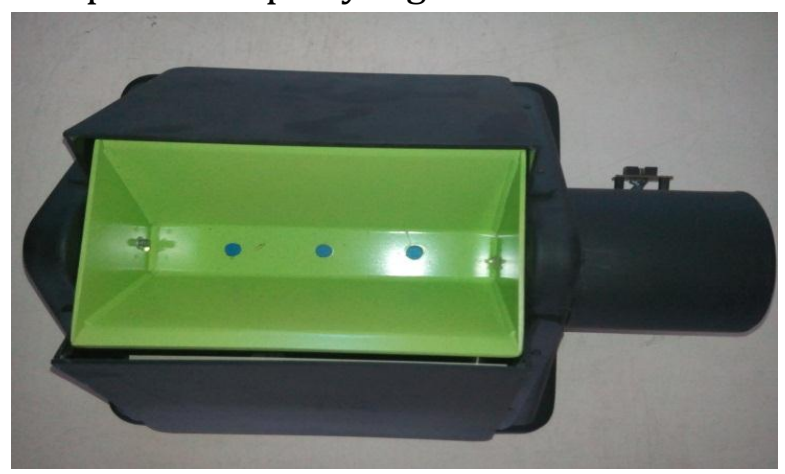

Gambar 3 : Tutup bak sampah hasil modifikasi (Hasil Penelitian)

Selanjutnya alat yang digunakan dalam pemodifikasian tutup bak sampah adalah :

$\begin{array}{ll}\text { 1. } & \text { Penggaris } \\ \text { 2. } & \text { Pensil } \\ \text { 3. } & \text { Sekrup }\end{array}$ 

4. $\quad$ Obeng
5. Bor Listrik
6. Gerinda
7. Tang

\section{HASIL DAN PEMBAHASAN}

Dari hasil penelitian yang dilakukan, dihasilkan suatu alat detektor kualitas oli berbasis mikrokontroler ATMega 16 seperti terlihat pada Gambar 4 berikut :

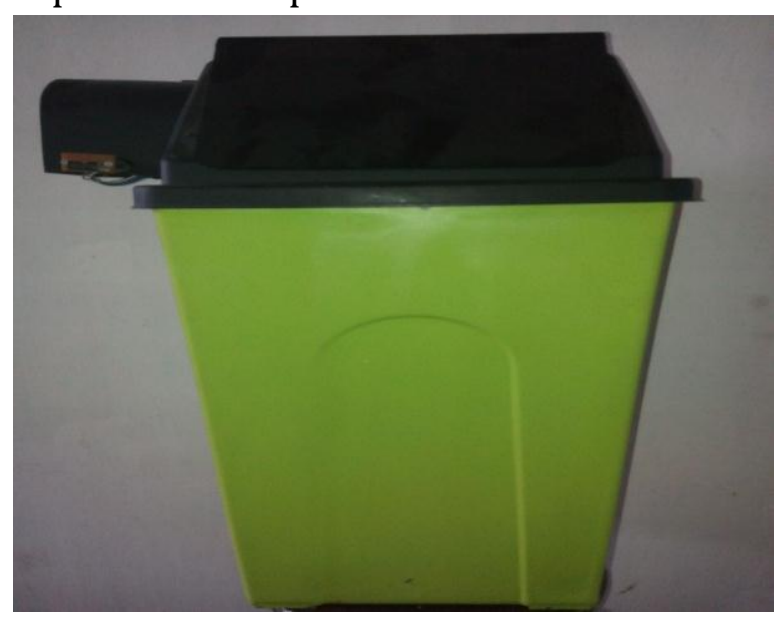

Gambar 4: Bak sampah otomatis

(Hasil Panelitian)

Berdasarkan hasil pengujian yang dilakukan pada bak sampah otomatis, kekurangan yang terdapat pada prototype bak sampah ini adalah tenaga yang digunakan untuk menjalankan bak sampah masih menggunakan sebuah power supply tegangan dan arus yang rendah sehingga jika memutar sebuah motor servo untuk meggerakkan tutup mekanik bak sampah mesti yang memiliki dimensi kecil. Seandainya jika menggunakan baterai, tegangan yang dibutuhkan sangat besar sehingga baterai akan cepat habis, tetapi memiliki keuntungan kondisinya lebih portable. Sebuah motor servo membutuhkan tegangan catu daya sebesar 12 Volt $D C$.

Hasil pengujian alat bak sampah otomatis akan dikaji pada pembahasan berikut ini. Pembahasan hasil pengujian alat meliputi pengujian catu daya, pengujian sensor infra merah dan pengujian sensor metal.

Berikut adalah Tabel 1 yang menampilkan hasil pengujian catu daya yang digunakan pada alat :

Tabel 1 : Hasil pengujian catu daya

\begin{tabular}{|c|c|c|c|c|c|c|}
\hline \multirow[b]{2}{*}{ No. } & \multirow{2}{*}{\multicolumn{2}{|c|}{ Pengukuran }} & \multicolumn{3}{|c|}{ Data (Volt) } & \multirow{2}{*}{$\begin{array}{l}\text { Rata- } \\
\text { rata } \\
\text { (Volt) }\end{array}$} \\
\hline & & & 1 & 2 & 3 & \\
\hline \multirow{3}{*}{1.} & \multirow{3}{*}{ Trafo } & & & & & \\
\hline & & $\begin{array}{l}\text { Input } \\
\text { AC }\end{array}$ & 220 & 220 & 220 & 220 \\
\hline & & $\begin{array}{l}\text { Output } \\
\text { AC }\end{array}$ & 15,9 & 16,00 & $\begin{array}{l}16 \\
00\end{array}$ & 15,97 \\
\hline \multirow{2}{*}{2.} & \multirow{2}{*}{$\begin{array}{l}\text { LM781 } \\
2\end{array}$} & $\begin{array}{l}\text { Input } \\
\text { AC }\end{array}$ & 16,71 & 16,72 & $\begin{array}{l}16 \\
71\end{array}$ & 16,71 \\
\hline & & $\begin{array}{l}\text { Output } \\
\text { DC }\end{array}$ & 11,89 & 11,89 & $\begin{array}{l}11 \\
90\end{array}$ & 11,89 \\
\hline \multirow{2}{*}{3.} & \multirow{2}{*}{$\begin{array}{l}\text { LM780 } \\
5\end{array}$} & $\begin{array}{l}\text { Input } \\
\text { AC }\end{array}$ & 11,89 & 11,89 & $\begin{array}{l}11, \\
90\end{array}$ & 11,89 \\
\hline & & $\begin{array}{l}\text { Output } \\
\text { DC }\end{array}$ & 4,92 & 4,93 & $\begin{array}{l}4,9 \\
3\end{array}$ & 4,93 \\
\hline
\end{tabular}

Hasil pengukuran yang telah dilakukan berdasarkan pengukuran tegangan keluaran IC 7805 menggunakan multimeter adalah 4,93 Volt DC. Idealnya regulator akan mengeluarkan tegangan 5 Volt $D C$. Penyimpangan keluaran untuk $I C$ 7805 sebesar : kesalahan $=5-4,93 / 5 \mathrm{x}$ $100 \%=0.014 \%$. (Sudjadi)

Hasil pengukuran yang telah dilakukan berdasarkan pengukuran tegangan keluaran IC7812 menggunakan multimeter adalah 11,89 Volt DC. Idealnya regulator akan mengeluarkan tegangan 12 Volt DC. Penyimpangan keluaran untuk $I C$ 7812 sebesar : kesalahan $=12-11,89 / 12$ x $100 \%=0.00918 \%$. Penyimpangan penyimpangan yang terjadi cukup kecil yaitu sebesar 0,0014\% dan 0,00916\%. Penyimpangan itu masih dapat diabaikan 
mengingat masih dalam daerah operasi komponen yang dicatu. Tegangan keluaran sudah mampu mengaktifkan alat yang dicatu oleh sumber catu daya dan menyediakan tegangan yang dibutuhkan oleh rancang bangun alat.

Untuk mempermudah analisa terhadap hasil pengujian catu daya untuk komponen trafo, maka berikut ini adalah Gambar 5 yang menampilkan plot grafik hasil pengujian trafo . (Winarno)

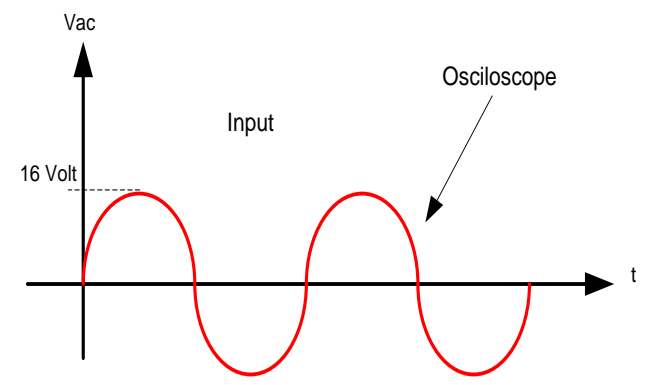

Gambar 5 : Grafik hasil pengujian trafo input -vsoutput (Hasil Penelitian)

Untuk mempermudah analisa terhadap hasil pengujian catu daya untuk komponen LM7812, maka berikut ini adalah Gambar 3.2 yang menampilkan plot grafik hasil pengujian LM7812 :

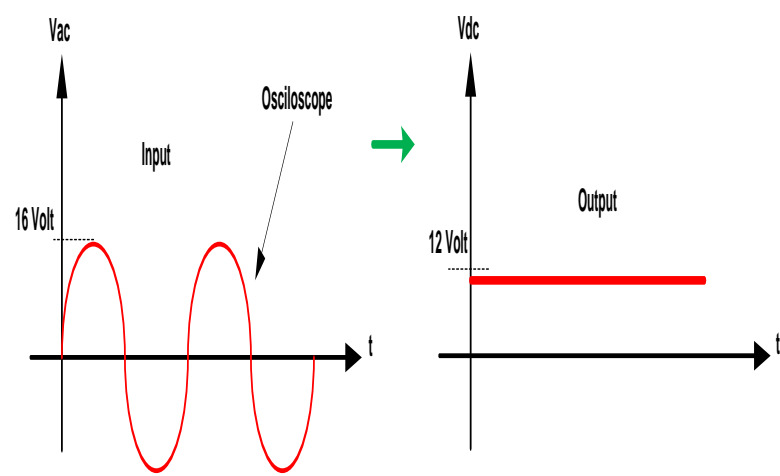

Gambar 6 : Grafik hasil pengujian LM7812 input -vsoutput (Putra, Agfianto Eko)

Untuk mempermudah analisa terhadap hasil pengujian catu daya untuk komponen LM7805, maka berikut ini adalah Gambar 3.3 yang menampilkan plot grafik hasil pengujian LM7805.

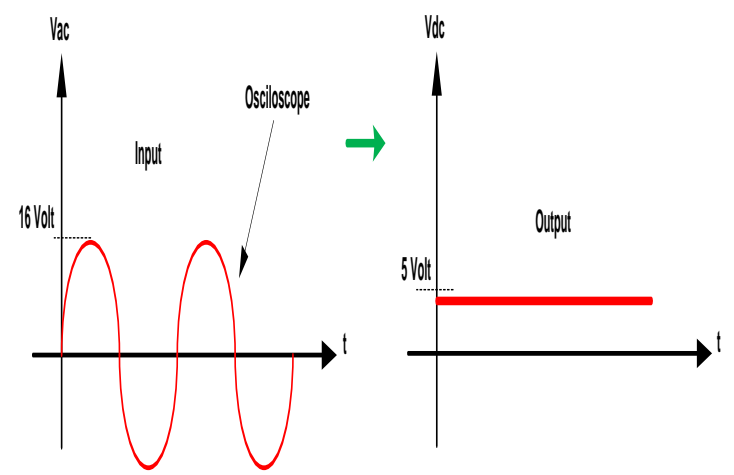

G

Gambar 7 : Grafik hasil pengujian LM7805 input vs- output (Hasil Penelitian)

Tabel 2 berikut adalah hasil pengujian sensor infra merah terhadap obyek yang melintasi atau menghalangi dengan photodioda :

Tabel 2 : Hasil pengujian sensor infra merah dan photodiode

\begin{tabular}{|l|l|l|l|}
\hline $\begin{array}{l}\text { Pengukuran } \\
\text { ke - }\end{array}$ & $\begin{array}{l}\text { Jarak antara } \\
\text { IR dengan } \\
\text { photodioda }\end{array}$ & $\begin{array}{l}\text { Tegangan } \\
\text { output }\end{array}$ & Logika \\
\hline 1 & $5 \mathrm{~cm}$ & 5 Volt & High \\
\hline 2 & $10 \mathrm{~cm}$ & 4,95 Volt & High \\
\hline 3 & $15 \mathrm{~cm}$ & 4,75 Volt & High \\
\hline 4 & $20 \mathrm{~cm}$ & 4,68 Volt & High \\
\hline 5 & $25 \mathrm{~cm}$ & 4,37 Volt & High \\
\hline 6 & $30 \mathrm{~cm}$ & 4,12 Volt & High \\
\hline 7 & $35 \mathrm{~cm}$ & 4,02 & High \\
\hline 8 & $40 \mathrm{~cm}$ & 1,12 & Low \\
\hline 9 & $45 \mathrm{~cm}$ & 0,93 & Low \\
\hline 10 & $50 \mathrm{~cm}$ & 0,40 & Low \\
\hline
\end{tabular}

Untuk mempermudah analisa terhadap hasil pengujian sensor infra merah dengan photodioda, maka berikut ini adalah Gambar 8 yang menampilkan plot grafik hasil pengujian sensor infra merah dengan photodioda : 


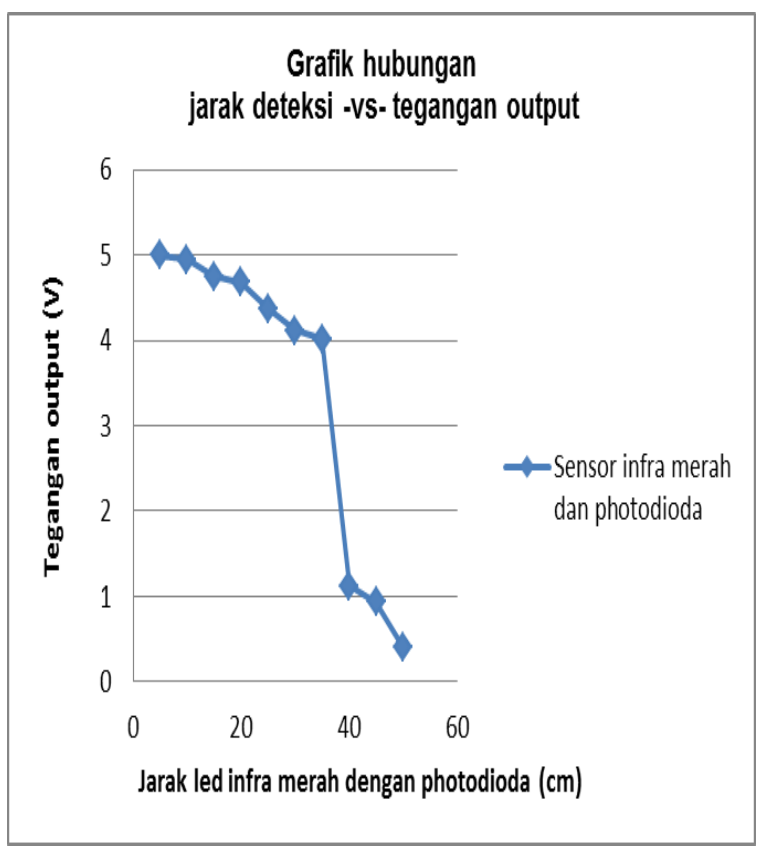

Gambar 8 : Grafik hasil pengujian sensor infra merah dengan photodiode (Hasil Penelitian)

Dari grafik diatas dapat dilihat bahwa jarak deteksi sensor sangat berpengaruh terhadap nilai tegangan output yang dihasilkan sensor, artinya semakin jauh jarak led infra merah memancarkan cahaya maka semakin sulit photodioda untuk menerima cahaya ataupun sinyal infra merah tersebut sehingga kategori aktif sebuah photodioda semakin sulit sehingga tegangan cenderung kepada output menuju mikrokontroler.

Untuk mempermudah analisa terhadap hasil pengujian sensor metal, maka berikut ini adalah Gambar 9 yang menampilkan plot grafik hasil pengujian sensor metal:

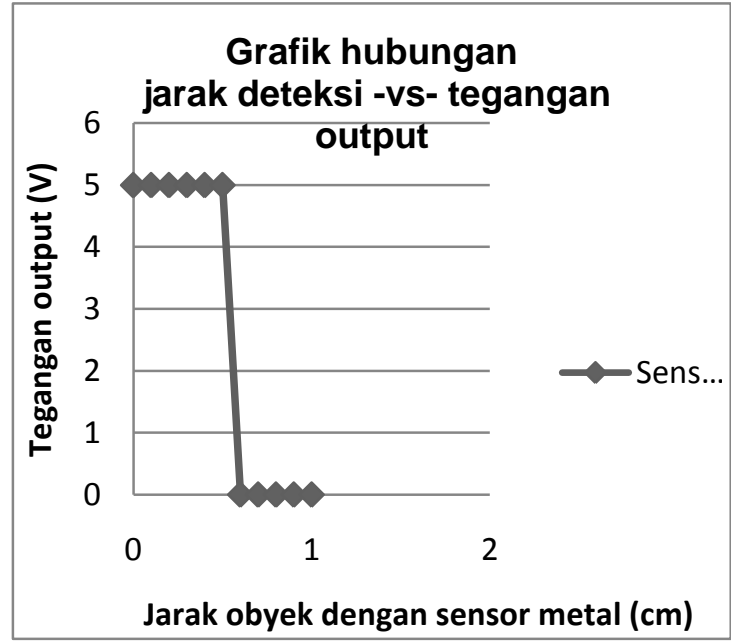

Gambar 9 : Grafik hasil pengujian sensor metal (Hasil Penelitian)

Gambar grafik di atas menunjukkan bahwa sensor metal memiliki sistem pendeteksian obyek yang akurat artinya jika obyek yang dideteksi benar-benar adalah metal maka tegangan output sensor akan bernilai tegangan 5 Volt dan apabila obyek yang dideteksi adalah bukan metal maka output tegangan sensor metal adalah bernilai 0 Volt.

Pengujian sistem secara menyeluruh artinya sistem yang telah terbentuk dan terangkai baik secara mekanik maupun elektrik yang telah tersusun menjadi satu sistem yang terintegrasi diuji fungsinya sebagai alat yang dapat menyeleksi jenis sampah dan membuangnya pada bak penampungannya masing-masing.

Adapun hasil pengujian yang telah dilakukan adalah dapat dilihat pada Tabel 3 berikut ini :

Tabel 3 : Hasil pengujian alat

\begin{tabular}{|c|c|c|c|}
\hline No. & $\begin{array}{c}\text { Jenis } \\
\text { bahan } \\
\text { sampah }\end{array}$ & $\begin{array}{c}\text { Arah } \\
\text { pembuangan } \\
\text { sampah }\end{array}$ & Kategori \\
\hline
\end{tabular}




\begin{tabular}{|c|c|c|c|}
\hline 1. & Kertas & Kiri & Benar \\
\hline 2. & Plastik & Kiri & Benar \\
\hline 3. & Kaca & Kiri & Benar \\
\hline 4. & Karet & Kiri & Benar \\
\hline 5. & Kayu & Kiri & Benar \\
\hline 6. & Metal & Kanan & Benar \\
\hline
\end{tabular}

Dari hasil pengujian sistem secara menyeluruh dapat dilihat pada Tabel 3 bahwa alat yang dirancang telah sesuai dengan yang diharapkan pada penelitian ini, dimana alat dapat menyeleksi jenis sampah dan membuangnya ke arah pembuangan ataupun tempat penampungan yang sesuai. Bisa dilihat dari Tabel tersebut bahwa ketika jenis sampah yang diteksi adalah bukan metal maka arah pergerakan pembuangan sampah adalah ke kiri dan sebaliknya jika obyekl tersebut adalah sampah jenis metal maka arah pergerakan adalah ke kanan.

\section{SIMPULAN}

Berdasarkan hasil yang dicapai dari keseluruhan proses pembuatan bak sampah otomatis berbasis mikrokontroler AT89S52, maka penulis menyimpulkan hasil pengujian dari sensor metal yang telah di-setting hanya dapat membaca sampah dari jarak $0-1 \mathrm{~cm}$. Servo akan aktif dan membuka tutup bak sampah dengan durasi 10 detik. Hasil pengujian dari sensor infra merah dan photodioda hanya dapat membaca sampah dari jarak 5 cm - $30 \mathrm{~cm}$ Seluruh sistem dapat bekerja sesuai tujuan penelitian sebagai sistem yang dapat membuka dan menutup kembali tutup bak sampah, dimana cara kerjanya melakukan seleksi terlebih dahulu jenis sampahnya dan selanjutnya membuangnya ke arah penampungan yang sesuai.

\section{DAFTAR PUSTAKA}

Budiharto, Widodo. 2005. Elektronika Digital dan Mikroprosesor. Yogyakarta : Penerbit Andi.

Putra, Agfianto Eko dan Nugraha Dhani. 2010. Tutorial Pemrograman Mikrokontroler AVR v1.0. Jurnal Elektronika : Yogyakarta

Putra, Agfianto Eko. 2010. Belajar Mikrokontroler AT89C51/52/55. Penerbit Gava Media.

Sudjadi, 2005. Teori dan Aplikasi Mikrokontroler : Aplikasi pada Mikrokontroler AT89C51. Yogyakarta : Penerbit Graha Ilmu.

Tague, N. R. (2005). The quality toolbox. (2th ed.). Milwaukee, Wisconsin: ASQ Quality Press. Available from http://asq.org/quality-press/displayitem/index.html?item=H1224.

Winarno. 2011. Bikin Robot itu Gampang. Jakarta Selatan : Penerbit PT Kawan Pustaka.

https://www.tetrixrobotics.com/Motors_and_ser vos Diakses pada 14 April

http://www.slideshare.net/kirnogadog/bab-10motor-servo Diakses pada 14April 2016

http://teknikelektronika.com/pengertian- Diakses pada 14April 2016

optocoupler-fungsi-prinsip-kerjaoptocoupler/.Diakses pada pada 16 April 2016

Info Perda Sampah. (2012). http: //www. harianjogja.com/2012/harianjogja/gunung -kidul/perda- sampah-denda-rp50-jutawarga-protes-179654/. Diakses tanggal 12 April 2016

Info Tempat Teratas Sumber Bakteri di Rumah. (2009). http://www.kalbe.co.id/files/cdk/files/158 20Tempatteratassumberbakteridirumah.p df/158_20Tempatteratassumberbakteridir umah.html/. Diakses tanggal 19 Maret 2016. 